\author{
Mediterranean Journals \\ Integrative Journal of Medical Sciences \\ 2021, Volume 8, ID 399 \\ DOI: $\underline{10.15342 / \mathrm{ijms.2021.399}}$
}

\title{
REVIEW
}

\section{LIFESTYLES AND COGNITION}

\author{
Shashi Agarwal \\ Center for Contemporary and Complementary Cardiology, USA
}

\begin{abstract}
Cognitive decline is a growing medical concern. It includes age-related cognitive decline, mild cognitive impairment, and dementia. Dementia results in considerable dysfunction in life and is associated with an increase in mortality. Since there is no cure at this time, attention is being increasingly directed towards prevention. Lifestyle factors, such as smoking, alcoholism, physical inactivity, poor diet, improper sleep, and loneliness are repeatedly being recognized as modifiable factors that can reduce cognitive decline. This manuscript briefly reviews the lifestyle-cognition relationship.
\end{abstract}

KEYWORDS: Lifestyles; Cognitive Decline; Smoking; Alcohol; Physical Activity; Diet, Obesity; Alzheimer's Disease; MCI

Correspondence: Dr Shashi Agarwal, Center for Contemporary and Complementary Cardiology.

Email: usacardiologist@gmail.com

Copyright (C) 2021 Agarwal S. This is an open access article distributed under the Creative Commons Attribution 4.0 International, which permits unrestricted use, distribution, and reproduction in any medium, provided the original work is properly cited

\section{INTRODUCTION}

Cognition, a normal function of the brain, consists of perceiving, processing, and administrating information [1]. This ability progressively declines when we age, and this is considered normal [2]. Mild cognitive impairment (MCI) results when the impairment in cognition is more severe than that which is age-related [3]. People with MCI are, however, able to perform normal activities and can compensate for small changes [4]. MCI prevalence is approximately 10\%-20\% worldwide [5]. People with MCI have a heightened risk of further cognitive decline and progression to dementia [4]. Dementia results in cognitive decline severe enough to interfere with social and occupational functioning [6]. The global prevalence of dementia is approximately 50 million, and this number is projected to reach 131.5 million by 2050 [7]. It is usually seen in the elderly population and it is estimated that it affects $5-8 \%$ of people aged $60+$ years [8]. Alzheimer's disease (AD) accounts for 50-70\% of dementia cases [9]. $\mathrm{AD}$ is a progressive disease [10], and the cognitive decline severely disturbs social and occupational functioning [6]. MCI and dementia greatly reduce the quality of life [11], and are associated with increased mortality [12].

Cognitive impairment is associated with both white matter inflammatory lesions and gray matter pathology, such as cortical lesions and brain atrophy, and this reflects neurodegeneration [13]. There is no cure for MCI or dementia [14]. The focus on healthy lifestyles and their impact on cognition is therefore gaining more attention in the medical circles [15].

\section{DISCUSSION}

Most diseases are only 20-35\% heritable [16] and are predominantly dependent on external factors [17]. One such factor is lifestyles. Lifestyles not only impart a significant effect on the genesis and progression of chronic diseases [18], but they also affect mortality [19]. Lifestyle behaviors such as smoking, heavy alcohol consumption, physical inactivity, and poor diet/obesity may be responsible for up to $60 \%$ of premature deaths [20]. According to Li et al., adherence to healthy lifestyles could prolong life expectancy at age 50 by 14.0 years in US females and 12.2 years in US males compared with individuals who adopted zero low-risk lifestyle factors [21]. Similar life extension benefits of following a healthy lifestyle have been documented in other countries [22].

Although some cognitive decline is considered 'normal' with aging, MCI and dementia are on the rise, in part due to the surge in the global the aging population [23]. Because there is no established treatment, the search for therapeutic intervention has now increasingly focused on lifestyles/health-related behaviors [15] Unhealthy behaviors have been consistently noted to increase the rate of cognitive decline. On the other hand, healthier lifestyles are associated with better cognitive function [24] and reduce the incidence and progression of $\mathrm{MCI}$ and dementia [15].

Smoking: Several studies reported acute exposure to nicotine induces cognitive enhancement [25]. Many psychiatric disorders are associated with cognitive impairments, including deficits in attention, working memory, and response inhibition function [26]. The shortterm enhancing effect of nicotine may explain the high rate of smoking in individuals with psychiatric disorders [27]. Some researchers have also suggested that nicotine may be therapeutic in Alzheimer's disease and several psychiatric 
disorders [25]. The acute nicotine related effect on cognition may also explain why smokers are unable to quit [28].

The cognition performance enhancement associated with smoking is however short-term [29]. With long term use, smoking harms the cognitive function [30]. It has been causally implicated in the development of neurodegenerative disorders [31] including AD [32] and other dementias [33]. Previous studies indicated that smokers were 1.9-4.3 times more likely to develop AD than non-smokers [34]. The Honolulu-Asia Aging Study noted a dose-response relationship with smoking amount and $\mathrm{AD}$ [35]. Smokers exhibit excessive oxidative stress, neuroinflammation, and impaired neuroprotection in the brain [36]. Brain studies reveal a thinner anterior cingulum and prefrontal lobe, and many other structural abnormalities in smokers [37].

Passive smoking increases the risk of cognitive impairment in older adults by $24 \%$ and this seems to be especially prominent with non-smokers [38]. Cigarette smoking at an earlier age appears to predict the onset of cognitive impairment at an older age [39]. This risk is directly related to the duration and intensity of smoking and subsides gradually following smoking cessation [40]. Tobacco is a teratogen that impairs fetal brain development and smoking during pregnancy harms the developing fetus [41].

Alcohol: Many studies have demonstrated that low to moderate alcohol intake may prevent cognition decline [42]. However, the relationship between alcohol intake and cognition is $U$ shaped [43]. Excessive alcohol intake and binge drinking are associated with an increased risk of cognitive decline and dementia [44]. Alcohol, when excessive, is neurotoxic to the prefrontal cortex and hippocampal regions of the brain and results in neurodegeneration [45]. The result is functional deficits, especially impairment of executive and motivational functions [46]. Prenatal alcohol exposure may hamper the children's cognitive development [47]

Physical exercise: Physical exercise helps retard cognition decline [48]. Studies have overwhelmingly demonstrated a relationship between physical inactivity and cognitive impairment, including AD [49]. A recent meta-analysis reported significant beneficial effects on cognitive outcomes with exercise in adults aged 50 and older [50]. Another meta-analysis concluded that those with a high level of physical activity showed a $38 \%$ less decline in cognitive performance (compared with adults not engaged in physical activity) during 1-12 years of follow-up [51]. A low to moderate level of physical exercise has also demonstrated a $35 \%$ less decline in cognitive function [51].

Diet: Nutrition is one of the modifiable risk factors for cognitive decline and AD dementia [52]. Several studies have documented that a poor diet promotes cognitive decline, including AD [53]. A prospective study of 3,718 elderly participants, showed that consumption of greater than two vegetable servings per day decreased cognitive decline over a 6-year follow-up [54]. These individuals appeared about 5 years younger on cognition testing [54]. In cognitively normal populations, the Mediterranean diet and dietary approaches to stop hypertension (DASH) diet, result in lesser age-related cognitive decline [55]. They also reduce the risk for the development of $\mathrm{MCI}$ or $\mathrm{AD}$
[56]. Consumption of fish is also associated with lesser cognitive decline in older people without AD [57].

Vegetables and fruits contain a plethora of antioxidant vitamins and nutrients, and they help counteract cognitive decline by reducing oxidative stress and inflammation [58]. Vegetables and fruits might also alter the gut microbiota, improving the gut-brain axis, and positively impacting cognitive health [59]. Fish is a good source of long-chain omega- 3 fatty acids, and this helps improve cognition [60].

Obesity and its relationship with cognition is mixed [61]. While obesity in midlife appears to be detrimental to cognitive decline, obesity in the old (over 65 years) has been reported to be detrimental, neutral, or even protective [62]. This "obesity paradox" may be explained by the survival of the less obese and healthier individuals as aging occurs [61]. It has also been suggested that this paradox may be insignificant if measurements of central obesity (WC and WtHR) are used, instead of relying solely on BMI [62].

Marijuana abuse: The two most well-studied cannabinoids are $\Delta 9$-tetrahydrocannabinol (THC), or its synthetic variants (dronabinol, nabilone), and cannabidiol (CBD). The use of THC has been associated with adverse cognitive effects [63].

Sleep: There is cumulating evidence that sleep quality and duration relate to cognitive processes. Bubu and colleagues, in a meta-analysis, found that sleep difficulty was associated with cognitive impairment in older adults [64]. It is estimated that the risk of developing dementia in patients with sleep disorders was 1.68 times greater [64]. Good quality and sufficient sleep is beneficial in individuals with $\mathrm{AD}$ [49].

Socialization: Lack of socialization, with a subjective feeling of loneliness, is associated with decreased cognitive function [65]. Loneliness leads to disturbed selfregulation which also promotes non-compliance with healthy lifestyles [66]. Lonely people are also more likely to be depressed. Depression contributes to cognitive decline [67]. Loneliness adversely affects the HPA axis inflammation and immunity, which influence cognitive decline [68].

\section{CONCLUSION}

Cognitive decline is multifactorial, and there is no known cure. Aging is the most common cause of a decrease in cognition. However, MCI and dementia are pathological and are worsened by unhealthy lifestyles. Healthy lifestyles include adherence to a normal body weight (BMI $\left.18.5-24.9 \mathrm{~kg} / \mathrm{m}^{2}\right)$, regular physical activity $(150 \mathrm{~min} /$ week of moderate physical activity), a healthy diet rich in fruits and vegetables, avoidance of alcohol and smoking, getting refreshing sleep (about 8 hours per day) and having a good social life. Most individuals with unhealthy behaviors usually indulge in other unhealthy activities also, and this further worsens cognitive decline.

\section{ACKNOWLEDGMENTS}

None.

\section{COMPETING INTERESTS}

The author declares no competing interests with this case.

\section{FUNDING SOURCES}

None. 


\section{REFERENCES}

[1] Chaves AS, dos Santos AM, Soares de Britto E Alves MT , Filho NS. Association between cognitive decline and the quality of life of hypertensive elderly individuals. Rev Bras Geriatr Gerontol. 2015;18(3):545-56. DOI: 10.1590/1809-9823.2015.14043

[2] Singh-Manoux, A., Kivimaki, M., Glymour, M. M., Elbaz, A., Berr, C., Ebmeier, K. P., et al. (2012). Timing of onset of cognitive decline: results from Whitehall II prospective cohort study. BMJ 344:d7622. DOI: $10.1136 / \mathrm{bmj} . \mathrm{d} 7622$

[3] Lin, P.-J.; Zhong, Y.; Fillit, H.M.; Chen, E.; Neumann, P.J. Medicare expenditures of Individuals with Alzheimer's Disease and related dementias or mild cognitive impairment before and after diagnosis. J. Am. Geriatr. Soc. 2016, 64, 1549-1557.

[4] Roberts, R.O.; Knopman, D.S. Classification and Epidemiology of MCI. Clin. Geriatr. Med. 2013, 29, 753772.

[5] Petersen RC. Clinical practice. mild cognitive impairment. N Engl J Med 2011;364:2227. DOI: 10.1056/NEJMcp0910237

[6] Draper, B.; Cations, M.; White, F.; Trollor, J.; Loy, C.; Brodaty, H.; Sachdev, P.; Gonski, P.; Demirkol, A.; Cumming, R.G.; et al. Time to diagnosis in young-onset dementia and its determinants: The inspired study. Int. J. Geriatr. Psychiatry 2016, 31, 1217-1224.

[7] Prince M, Ali G-C, Guerchet M, et al. Recent global trends in the prevalence and incidence of dementia, and survival with dementia. Alzheimers Res Ther2016;8:23. DOI: $10.1186 / \mathrm{s} 13195-016-0188-8$

[8] World Health Organisation. Global Action Plan on the Public Health Response to Dementia 2017-2020; World Health Organisation: Geneva, Switzerland, 2017

[9] American Psychiatric Association. Diagnostic and Statistical Manual of Mental Disorders, 5th ed.; American Psychiatric Association: Washington, DC, USA, 2013.

[10] Galvin JE and Sadowsky CH. Practical guidelines for the recognition and diagnosis of dementia. J Am Board Family Med. 2012;25(3):367-382

[11] Landeiro F, Mughal S, Walsh K, et al. ROADMAP consortium. Health-related quality of life in people with predementia Alzheimer's disease, mild cognitive impairment or dementia measured with preference-based instruments: a systematic literature review. Alzheimers Res Ther. 2020 Nov 18;12(1):154. DOI: $10.1186 / \mathrm{s} 13195-020-00723-1$

[12] Dewey ME, Saz P. Dementia, cognitive impairment and mortality in persons aged 65 and over living in the community: A systematic review of the literature. Int $\mathbf{J}$ Geriatr Psychiatr. 2001;16:751-761.

[13] Calabrese M, Poretto V, Favaretto A, et al. . Cortical lesion load associates with progression of disability in multiple sclerosis. Brain 2012;135:2952-2961.

[14] Campbell, S.; Manthorpe, J.; Samsi, K.; Abley, C.; Robinson, L.; Watts, S.; Bond, J.; Keady, J. Living with uncertainty: Mapping the transition from pre-diagnosis to a diagnosis of dementia. J. Aging Stud. 2016, 37, 40-47.

[15] Kivipelto, M., Mangialasche, F., and Ngandu, T. (2018). Lifestyle interventions to prevent cognitive impairment, dementia and Alzheimer disease. Nat. Rev. Neurol. 14, 653-666. DOI: 10.1038/s41582-018-0070-3

[16] Gluckman TJ, Kovacs RJ, Stone NJ, Damalas D, Mullen JB, Oetgen WJ. The ASCVD risk estimator app: from concept to the current state. J. Am. Coll. Cardiol., 67 (2016), pp. 350-352 DOI: $10.1016 /$ j.jacc.2015.10.068

[17] G. Shiels, S. Buchanan, C. Selman, P. Stenvinkel.Allostatic load and ageing: linking the microbiome and nutrition with age-related health. Biochem. Soc. Trans., 47 (2019), pp. 1165-1172 DOI: 10.1042/BST20190110

[18] Li Y, Schoufour J, Wang DD, et al. Healthy lifestyle and life expectancy free of cancer, cardiovascular disease, and type 2 diabetes: prospective cohort study. BMJ. 2020;368:16669. Published 2020 Jan 8 DOI: $10.1136 / \mathrm{bmj} .16669$
[19] Loef M, Walach $H$. The combined effects of healthy lifestyle behaviors on all cause mortality: a systematic review and meta-analysis. Prev Med 2012;55:163-70. DOI: 10.1016/j.ypmed.2012.06.017

[20] Mokdad AH, Forouzanfar MH, Daoud F, et al. Global burden of diseases, injuries, and risk factors for young people's health during 1990-2013: a systematic analysis for the Global Burden of Disease Study 2013. Lancet 2016;387:2383-401. DOI: $10.1016 / \mathrm{S} 0140-6736(16) 00648-6$

[21] Yanping Li, An Pan, Dong D. Wang, et al. Impact of Healthy Lifestyle Factors on Life Expectancies in the US Population. Circulation. 2018;138:345-355.

[22] O’Doherty MG, Cairns K, O’Neill V, et al. Effect of major lifestyle risk factors, independent and jointly, on life expectancy with and without cardiovascular disease: results from the Consortium on Health and Ageing Network of Cohorts in Europe and the United States (CHANCES). Eur J Epidemiol. 2016; 31:455-468. DOI: $10.1007 / \mathrm{s} 10654-015-0112-8$

[23] https://www.who.int/ageing/publications/global_health.pd f. Accessed January 8, 2021

[24] Huang Zhezhou, Guo Yanfei, Ruan Ye, et al. Associations of Lifestyle Factors With Cognition in CommunityDwelling Adults Aged 50 and Older: A Longitudinal Cohort Study. Aging Neurosci., 09 November 2020. DOI: $10.3389 /$ fnagi.2020.601487

[25] Newhouse P., Kellar K., Aisen P., White H., Wesnes K., Coderre E., Pfaff A., Wilkins H., Howard D., Levin E.D. Nicotine treatment of mild cognitive impairment: A 6month double-blind pilot clinical trial. Neurology. 2012;78:91-101. DOI: 10.1212/WNL.0b013e31823efcbb

[26] Millan M.J., Agid Y., Brüne M., et al. Cognitive dysfunction in psychiatric disorders: characteristics, causes and the quest for improved therapy. Nat. Rev. Drug Discov. 2012;11(2):141-168. DOI: $10.1038 / \mathrm{nrd} 3628$

[27] de Leon J., Diaz F.J. A meta-analysis of worldwide studies demonstrates an association between schizophrenia and tobacco smoking behaviors. Schizophr. Res. 2005;76(23):135-157. DOI: $10.1016 /$ j.schres.2005.02.010

[28] Besson M., Forget B. Cognitive dysfunction, affective states, and vulnerability to nicotine addiction: A multifactorial perspective. Front. Psychiatry. 2016;7:160. DOI: $10.3389 /$ fpsyt. 2016.00160

[29] Newhouse P.A., Potter A., Singh A. Effects of nicotinic stimulation on cognitive performance. Curr. Opin. Pharmacol. 2004;4:36-46. DOI : $10.1016 /$ j.coph.2003.11.001

[30] Hill R.D., Nilsson L.G., Nyberg L., Backman L. Cigarette smoking and cognitive performance in healthy Swedish adults. Age Ageing. 2003;32:548-550. DOI: 10.1093 /ageing/afg067

[31]Zhan Y, Fang F. Smoking and amyotrophic lateral sclerosis: a mendelian randomization study. Ann Neurol. 2019;85(4):482-484 DOI: 10.1002 /ana. 25443

[32] Durazzo TC, Mattsson N, Weiner MW; Alzheimer's Disease Neuroimaging Initiative. Smoking and increased Alzheimer's disease risk: a review of potential mechanisms. Alzheimers Dement. 2014; 10(3) (suppl): S122-S145. DOI: 10.1016/j.jalz.2014.04.009

[33] Khan U., Porteous L., Hassan A., Markus H. S. (2007). Risk factor profile of cerebral small vessel disease and its subtypes. J. Neurol. Neurosurg. Psychiatry 78 702-706. DOI: $10.1136 /$ jnnp.2006.103549

[34] Anstey K. J., von Sanden C., Salim A., O’Kearney R. (2007). Smoking as a risk factor for dementia and cognitive decline: a meta-analysis of prospective studies. Am. J. Epidemiol. DOI: 166 367-378. 10.1093/aje/kwm116

[35] Tyas S. L., White L. R., Petrovitch H., Webster Ross G., Foley D. J., Heimovitz H. K., et al. (2003). Mid-life 
smoking and late-life dementia: the honolulu-asia aging study. Neurobiol. Aging 24 589-596. DOI: $10.1016 / \mathrm{s} 0197-4580(02) 00156-2$

[36] Liu Y, Li H, Wang J, et al. Association of Cigarette Smoking With Cerebrospinal Fluid Biomarkers of Neurodegeneration, Neuroinflammation, and Oxidation. JAMA Netw Open. 2020 Oct 1;3(10):e2018777. DOI: $10.1001 /$ jamanetworkopen.2020.18777

[37] Karama S., Ducharme S., Corley J., Chouinard-Decorte F., Starr J. M., Wardlaw J. M., et al. (2015). Cigarette smoking and thinning of the brain's cortex. Mol. Psychiatry $20778-$ 785 . DOI: $10.1038 / \mathrm{mp} .2014 .187$

[38] He F, Li T, Lin J, Li F, Zhai Y, Zhang T, Gu X, Zhao G. Passive Smoking Exposure in Living Environments Reduces Cognitive Function: A Prospective Cohort Study in Older Adults. Int J Environ Res Public Health. 2020 Feb 21;17(4):1402. DOI: 10.3390/ijerph17041402

[39] Velusami D, Venkatesh S, Soundariya K. Effect of smoking on neurocognitive function. June 2020. Int. J Basic Appl. Physiol.,5(1),2016.

[40] Mons U, Schöttker B, Müller H, Kliegel M, Brenner H. History of lifetime smoking, smoking cessation and cognitive function in the elderly population. Eur $\mathbf{J}$ Epidemiol. 2013 Oct;28(10):823-31. DOI: $10.1007 / \mathrm{s} 10654-013-9840-9$

[41] United States Department of Health and Human Services, Substance Abuse and Mental Health Services Administration, Center for Behavioral Health Statistics and Quality (2012). National survey on drug use and health, 2012 [Data set]. National survey on drug use and health (NSDUH) series. ICPSR - Interuniversity Consortium for Political and Social Research. DOI: $10.3886 /$ ICPSR34933.v3

[42] Wood AM, Kaptoge S, Butterworth AS, et al. ; Emerging Risk Factors Collaboration/EPIC-CVD/UK Biobank Alcohol Study Group . Risk thresholds for alcohol consumption: combined analysis of individual-participant data for 599912 current drinkers in 83 prospective studies. Lancet. 2018;391(10129):1513-1523. DOI: $10.1016 / \mathrm{S} 0140-6736(18) 30134-X$

[43] Xu W, Wang H, Wan Y, et al. Alcohol consumption and dementia risk: A dose-response meta-analysis of prospective studies. Eur J Epidemiol. 2017;32(1):31-42. DOI: $10.1007 / \mathrm{s} 10654-017-0225-3$

[44] Cheng C, Huang CL, Tsai CJ, Chou PH, Lin CC, Chang CK. Alcohol-Related Dementia: A Systemic Review of Epidemiological Studies. Psychosomatics. 2017 JulAug;58(4):331-342. DOI: 10.1016/i.psym.2017.02.012

[45] Clark D.B., Thatcher D.L., Tapert S.F. Alcohol, psychological dysregulation, and adolescent brain development. Alcohol. Clin. Exp. Res. 2008;32:375-385. DOI: $10.1111 / \mathrm{j} .1530-0277.2007 .00601 . \mathrm{x}$

[46] Oscar-Berman M., Marinkovic K. Alcohol: Effects on neurobehavioral functions and the brain. Neuropsychol. Rev. 2007; 17:239-257.

DOI: $10.1007 / \mathrm{s} 11065-007-9038-6$

[47] Römer, P.; Mathes, B.; Reinelt, T.; Stoyanova, P.; Petermann, F.; Zierul, C. Systematic review showed that low and moderate prenatal alcohol and nicotine exposure affected early child development. Acta Paediatr. 2020, 109, 2491-2501.

[48] Cai H, Li G, Hua S, Liu Y, Chen L. Effect of exercise on cognitive function in chronic disease patients: a metaanalysis and systematic review of randomized controlled trials. Clin Interv Aging. 2017;12:773-783. Published 2017 May 11. DOI: $10.2147 / C I A . S 135700$

[49] Yu JT, Xu W, Tan CC, et al. Evidence-based prevention of Alzheimer's disease: systematic review and meta-analysis of 243 observational prospective studies and 153 randomised controlled trials. J Neurol Neurosurg Psychiatry. 2020;91(11):1201-1209. DOI: 10.1136/innp-2019-321913

[50] Zhezhou Huang, Yanfei Guo, Ye Ruan, et al. Associations of Lifestyle Factors With Cognition in Community-
Dwelling Adults Aged 50 and Older: A Longitudinal Cohort Study. Front. Aging Neurosci., 09 November 2020.

[51] Sofi, F., Valecchi, D., Bacci, D., Abbate, R., Gensini, G. F., Casini, A., et al. (2011). Physical activity and risk of cognitive decline: a meta-analysis of prospective studies. J. Intern. Med. 269, 107-117. DOI: $10.1111 / \mathrm{j} .1365-2796.2010 .02281 . \mathrm{x}$

[52] Gehlich, K. H., Beller, J., Lange-Asschenfeldt, B., Köcher, W., Meinke, M. C., and Lademann, J. (2019). Fruit and vegetable consumption is associated with improved mental and cognitive health in older adults from non-Western developing countries. Public Health Nutr. 22, 689-696.

[53] Fieldhouse JLP, Doorduijn AS, de Leeuw FA, et al. A Suboptimal Diet is Associated with Poorer Cognition: The NUDAD Project. Nutrients. 2020;12(3):703. Published 2020 Mar 6. DOI: $\underline{10.3390 / \mathrm{nu} 12030703}$

[54] Morris, M. C., Evans, D. A., Tangney, C. C., Bienias, J. L., and Wilson, R. S. (2006). Associations of vegetable and fruit consumption with age-related cognitive change. Neurology 67, 1370-1376. DOI: 10.1212/01.wnl.0000240224.38978.d8

[55] van den Brink A.C., Brouwer-Brolsma E.M., Berendsen A.A., van de Rest O. The Mediterranean, Dietary Approaches to Stop Hypertension (DASH), and Mediterranean-DASH Intervention for Neurodegenerative Delay (MIND) Diets Are Associated with Less Cognitive Decline and a Lower Risk of Alzheimer's Disease-A Review. Adv. Nutr. 2019;10:1010-1065. DOI: $10.1093 /$ advances/nmz054

[56] Fieldhouse JLP, Doorduijn AS, de Leeuw FA, et al. A Suboptimal Diet is Associated with Poorer Cognition: The NUDAD Project. Nutrients. 2020;12(3):703. Published 2020 Mar 6. DOI: $\underline{10.3390 / \mathrm{nu} 12030703}$

[57] Fotuhi, M., Mohassel, P., Yaffe, K. Fish consumption, long-chain omega-3 fatty acids and risk of cognitive decline or Alzheimer disease: A complex association. Nat. Rev. Neurol. 2009, 5, 140-152.

[58] Gehlich, K. H., Beller, J., Lange-Asschenfeldt, B., Köcher, W., Meinke, M. C., and Lademann, J. (2019). Fruit and vegetable consumption is associated with improved mental and cognitive health in older adults from non-Western developing countries. Public Health Nutr. 22, 689-696. DOI: $10.1017 / \mathrm{S} 1368980018002525$

[59] Pistollato, F., Sumalla Cano, S., Elio, I., Masias Vergara, M., Giampieri, F., and Battino, M. (2016). Role of gut microbiota and nutrients in amyloid formation and pathogenesis of Alzheimer disease. Nutr. Rev. 74, 624634. DOI: 10.1093/nutrit/nuw023

[60] van der Wurff ISM, Meyer BJ, de Groot RHM. Effect of Omega-3 Long Chain Polyunsaturated Fatty Acids (n-3 LCPUFA) Supplementation on Cognition in Children and Adolescents: A Systematic Literature Review with a Focus on n-3 LCPUFA Blood Values and Dose of DHA and EPA. Nutrients. 2020 Oct 12;12(10):3115 DOI: $10.3390 /$ nu 12103115

[61] Bischof, G. N., and Park, D. C. (2015). Obesity and aging: consequences for cognition, brain structure, and brain function. Psychosom. Med. 77, 697-709. DOI: 10.1097/PSY.0000000000000212

[62] Monda, V., La Marra, M., Perrella, R., Caviglia, G., Iavarone, A., Chieffi, S., et al. (2017). Obesity and brain illness: from cognitive and psychological evidences to obesity paradox. Diabetes Metab. Syndr. Obes. 10, 473479 DOI: $10.2147 / \mathrm{DMSO} . \mathrm{S} 148392$

[63] Gottschling S, Ayonrinde O, Bhaskar A, Blockman M, D'Agnone O, Schecter D, Suárez Rodríguez LD, Yafai S, Cyr C. Safety Considerations in Cannabinoid-Based Medicine. Int J Gen Med. 2020 Dec 1;13:1317-1333. DOI: $\underline{10.2147 / I J G M . S 275049}$

[64] Bubu OM, Brannick M, Mortimer J, et al. Sleep, cognitive impairment, and Alzheimer's disease: a systematic review and meta-analysis. Sleep. 2017;40(1):zsw032. DOI: 10.1093/sleep/zsw032 
[65] Lara E, Caballero FF, Rico-Uribe LA, Olaya B, Haro JM, Ayuso-Mateos JL, Miret M. Are loneliness and social isolation associated with cognitive decline? Int $\mathrm{J}$ Geriatr Psychiatry. 2019 Nov;34(11):1613-1622. DOI: $10.1002 /$ gps. 5174

[66] Baumeister R.F., DeWall C.N., Ciarocco N.J., Twenge JM. (2005). Social exclusion impairs self-regulation. Journal of Personality and Social Psychology, 88(4), 589604.

[67] Jaremka LM, Andridge RR, Fagundes CP, Alfano CM, Povoski SP, Lipari AM, Agnese DM, Arnold MW, Farrar WB, Yee LD, Carson WE 3rd, Bekaii-Saab T, Martin EW
Jr, Schmidt CR, Kiecolt-Glaser JK. Pain, depression, and fatigue: loneliness as a longitudinal risk factor. Health Psychol. 2014 Sep;33(9):948-57.

DOI: $10.1037 / \mathrm{a} 0034012$

[68] Cacioppo J.T., Ernst J.M., Burleson M.H., et al. (2000). Lonely traits and concomitant physiological processes: the MacArthur social neuroscience studies. Int $\mathrm{J}$ Psychophysiol, 35(2-3), 143-154.

DOI: $\underline{10.1016 / \mathrm{s} 0167-8760(99) 00049-5}$ 